\title{
The pornography consumer as Other
}

\section{Alan McKee}

\section{Introduction}

It might be thought to be self-evident that if we want to understand pornography consumption we should include the perspective of the people who actually consume pornography. However in a 2011 book chapter the Australian academic Helen Pringle argues strongly that we should not: 'after all, we do not consult racists in formulating laws against hate speech on the basis that they are involved in and know a lot about racism' (Pringle, 2011, p. 127). Pringle's position is merely the radical expression of what is a curious characteristic of research into pornography: that in trying to understand pornography, the people who consume it are consistently silenced - or, to put it another way (as I explain below), 'Othered'.

In order to understand how this came to be the case - and why it matters - we need to understand how the consumption of pornography, and the ways in which this consumption have been represented, have changed over the years.

\section{A history of pornography consumers}

Historian Walter Kendrick has shown that although sexually explicit representations have existed throughout human history, it is only in the nineteenth century in Western countries that 'pornography' emerges as a distinct category of human culture. The English word itself was used for the first time in print in 1850 to describe the sexually explicit artefacts uncovered at Pompeii, and Kendrick shows how in the first decades of its use art historians and museum curators struggled to ensure that the only properly educated white gentlemen were allowed to see pornography. As one of these curators wrote in 1877:

We have taken all the prudential measures applicable to such a collection of engravings and text. We have endeavoured to make its reading inaccessible, so to speak, to poorly educated person, as well as those whose sex and age forbid any 
exception to the laws of decency and modesty (Barré, quoted in Kendrick, 1996, p. 15)

So long as pornography could be kept private, only available for the edification of welleducated people, and so long as the pornography consumer was a connoisseur rather than a pleb, pornography consumption was not a problem. But, as Kendrick notes, 'books being sluttish as they are' (Kendrick, 1996, p. 15), over the succeeding decades pornography escaped from the 'secret museum' and circulated freely among the wrong types of people - particularly the working classes. The problematic 'pornography consumer' (the wrong kind of consumer) was born. And, at the same moment, were born campaigns against pornography.

In the first half of the twentieth century these campaigns tended to be organised in terms of morality - 'decency' and 'family values' (Strub, 2006). The 1960s and 70s, however, saw radical changes in social organisation in Western countries. The rise of feminism, of the civil rights movement, and of gay liberation, saw public attacks on conventional structures of authority. Condemnations of pornography that relied on appeals to a shared religious conviction grew increasingly unconvincing. Conservatives who wished to attack pornography needed a new approach to 'proving' the harms done by pornography.

In this history, 1970 is an important year: the year that the US President's Commission on Obscenity and Pornography released its report on the place of pornography in American life and emphatically placed social scientific research methods at the heart of understanding the people who consume pornography. The Commission had been formed in 1967 as part of the progressive 'Great Society' social program of president Lyndon Johnson (Lewis, 2008, p. 8), and tasked to

analyse obscenity law and recommend a useful legal definition for obscenity ... explore the nature and volume of traffic in pornographic materials ... study the effect of such materials on the public ... [and] recommend legislation to regulate such volume and traffic (Lewis, 2008, p. 10).

As the first major review of pornographic materials by a government body, it commissioned numerous empirical studies on pornography effects, which comprised the bulk of the final report. 
The research and publication of this report marks a turning point for academic research on pornography. Before 1970 it is difficult to find any academic journal articles that investigate the relationship between pornography and violence; after 1970, a small flood of social science research in this area appears - and it has never stopped.

The findings presented in the Commission's report are not in themselves particularly important. Based on these studies, however, the report concluded that there was no reliable evidence of negative effects from the consumption of pornography, and recommended its decriminalization (Lewis, 2008, p. 13). More important than this finding was the fact that the report made the relationship between pornography and violence the central concern when thinking about the government's role in managing sexually explicit material - more so than questions of morality or decency. In particular it suggested that psychology was the most suitable academic discipline for addressing this concern. Rather than humanities methods that study the different ways in which people might use pornography, or sociological approaches that would explore the cultures within which pornography circulated, psychology would now be the most authoritative source of evidence about pornography consumers.

The main research methods that psychology has applied to the study of pornography have been quantitative, with experimental work having a central place. For example, researchers may expose subjects in the laboratory to (usually violent) pornography and then measure changes in their aggressiveness and attitudes towards women. The results of this research have been contradictory. There is general consensus that viewing non-violent pornography does not produce any significant effects. In terms of violent pornography, the results are more variable. Some researchers have managed to produce significant negative effects in consumers from viewing violent pornography in laboratory experiments. These include increased tendencies to aggression against women (Donnerstein \& Berkowitz, 1981), an acceptance of rape myths (Malamuth \& Check, 1981) and decreased support for women's rights (Zillmann \& Bryant, 1984). However, other researchers have been unable to replicate these results (Barak \& Fisher, 1997; Linz, Donnerstein, \& Penrod, 1988). So in some laboratory studies there is a link between the consumption of violent pornography and negative attitudes - but this conflicts with studies of actual sex offenders which refuse such a correlation (Fisher \& Grenier, 1994, p. 25). 
For the purposes of this chapter, a key element of laboratory experiments into pornography is that they do not recruit people who use pornography in their everyday life. Rather, they tend to recruit college students, many of whom are not consumers of pornography. These cohorts are then shown material that many find upsetting or distasteful (violent pornography), in public settings where they are not allowed to masturbate (most consumers of pornography masturbate while consuming the genre) (Potter, 1996, p. 111). In short, we can say that laboratory experiments tell us little about consumers of pornography in the world beyond the laboratory. They rather tell us about the effects of pornography on people who may, or may not, be pornography consumers, of being exposed involuntarily to pornography that they may find upsetting, in unfamiliar, non-sexual surroundings. Such studies do not explore the ways in which people who regularly use pornography make sense of its place in their lives. Indeed, not only do we not hear actual porn consumers' voices in these statistical analyses, but subjects are-as is common in psychological testingdeliberately misled as to the purpose of the experiments so that they do not know that their attitudes towards pornography are of interest (see, for example, Donnerstein \& Berkowitz, 1981).

Even in surveys of actual pornography consumers there is not always space for them to make their voices heard (Davies, 1997; Padgett, Brislin-Slütz, \& Neal, 1989; Potter, 1996; Richters, Grulich, de Visser, Smith, \& Rissel, 2003). Surveys are often quantitative in nature, which does not allow consumers to explain the meanings that pornography consumption holds for them, or to draw attention to what, for them, are the most important aspects of the genre.

In short, the dominant modes of academic research into pornography consumption have neglected the voices or experiences of people who actually consume pornography.

\section{Journalistic coverage of pornography consumption}

The situation is similar in journalistic coverage of pornography consumption. Consumers of pornography are the objects of much controversy in the news media. We see ongoing debates about the kinds of people who consume pornography, and the 
effects it has on their attitudes towards relationships, violence, and crime. There has been concern that pornography can 'damage' people (Hamilton, quoted in Symons, 2004, p. 4) - particularly young people. Commentators worry that pornography 'plays on the confusion and ultimate emotional sterility of those who use it' (Shanahan, 2004, p. 13). There is an ongoing concern that 'exposure to pornography' can turn people into sex offenders (Fewster, 2004), including paedophiles and gang rapists (Hamilton, 2004). Some argue that it can create unrealistic expectations of sex, and put people off the reality of sexual relationships (Hamilton, 2004). Other commentators assert that pornography contributes to a general increase in violent crime in our society (Pell, 2004), and that it is addictive and is turning people into 'junkies' (Anon, 2004). The voices most commonly heard in these news stories are those of opinion columnists, politicians, church leaders, and academic researchers. The voices of pornography consumers themselves are rarely published. Indeed, the only consumers of pornography regularly heard to speak in news stories are those who name themselves as 'addicts' and are seeking to stop watching the genre (see, for example, Taylor, 2005) $)^{\mathrm{i}}$

In both psychological research and journalistic coverage, pornography consumers are seen but not heard. They are represented, and spoken for, by others. They are not allowed to represent themselves.

\section{What is Othering?}

In her germinal 1949 book The Second Sex Simone de Beauvoir argued that in patriarchal cultures, women are 'the Other':

She is defined and differentiated with reference to man and not he with reference to her; she is the incidental, the inessential as opposed to the essential. He is the Subject, he is the Absolute - she is the Other (de Beauvoir, 2014 [1949])

In his 1978 book Orientalism (Said, 1995 [1978]) Edward Said expanded this argument to address explicitly the ways in which representation contributes to this process. He argued that throughout recorded history Western representations of 'the Orient' (the 'Middle East' and 'Far East') have been linked by the fact that they have 
not involved self-representations by the people who lived in this geographical area. Westerners have created their own versions of 'the Orient' that make sense according to Western logics, and that create a unified vision that claims that it is sensible to discuss 'the Orient' as a whole, and where everyone who lives there can be described as having similar characteristics:

there is no question of an exchange between [their] views and an outsider's: no dialogue, no discussion, no mutual recognition. There is a flat assertion of quality (Said, 1985, p. 8)

In short, Said argues, the 'Orient' has been Europe's 'silent Other' (Said, 1985, p. 5). For Said the important point is not whether or not these representations are 'accurate' or 'stereotypes' - he notes that there is no such thing as a single accurate representation that would cover every person who lives in all of these countries. Rather, his point is that these representations are created solely by outsiders. The peoples of the 'Orient' 'cannot represent themselves, they must therefore be represented by others' (Said, 1985, p. 7).

Said goes on to argue that there are political implications in such forms of representation: 'this, I submit, is neither science, nor knowledge, nor understanding: it is a statement of power and a claim for absolute authority' (Said, 1985, p. 8). He calls

such a relation between Western writing ... and Oriental silence the result of and the sign of the West's great cultural strength, its will to power over the Orient (Said, 1995 [1978], p. 94)

The concept of the 'Other' has proven productive for cultural theory. From its initial applications to gender and colonial relations between national, ethnic and racial groups the term has been expanded to include, for example, queer groups (Essig, 1999) and the working classes (Lawler, 2005). In each case the argument has been made that by excluding a group from the production of their own representation, a power relationship is being played out. An analysis of academic and journalistic representations of pornography consumers demonstrates the same play of power in the ways that they are represented. 
Despina Chronaki has shown that young people learn about sex from journalism, among other sources. And the version of sex they learn about from the news is not a positive one: newspapers are determined to protect young people from the 'perversity of their own sexuality'(Chronaki, in press). We have evidence that, at least since the 1950s, significant numbers of adolescents have sought out sexually explicit material as part of their sexual learning - a recent survey of pornography consumers found that of those growing up in the period before the end of the 1950s, 36.7\% had first seen pornography before the age of sixteen (McKee, Albury, \& Lumby, 2008, p. 37). A 2008 study suggested that, while pre-adolescent exposure (prior to age 13) remains 'relatively uncommon', over $90 \%$ of boys under 18 , and over $60 \%$ of girls, had seen sexually explicit material (Sabina, Wolak, \& Finkelhor, 2008). These young people find themselves in the strange situation where they are part of a large group that engages in a certain behaviour (viewing sexually explicit images), but the public discourses that explain the meaning of that behaviour exclude the voices of anyone who actually does it. It is the non-consumers (or, at least, people who present themselves publicly as non-consumers) in academia and journalism who get to set the agenda on how this behaviour should be understood.

The example of Professor Gail Dines' publicity tour for her book Pornland: How Porn has Hijacked Our Culture (Dines, 2010b) is typical of this 'othering'. Dines travelled the world receiving extensive news coverage for her argument that everyone who consumes porn is necessarily damaged by it - and becomes damaging to other people:

Boys and men don't realize the power they're giving away to pornography. They don't understand the power it has to shape who they are, their sexuality, and their sexual identity (Avard, 2010)

She talks about the damage that young people are doing to themselves by consuming porn:

Children who are 111/2 years old are now looking at pornography because it comes straight into the home. There's no limit on how much you can access ... So what happens is that desensitization sets in that much quicker and that much earlier. In order to keep the consumer base going, the pornographers have to keep upping the ante. They make it more violent, body-punishing, or abusive as a way to keep men interested. When you think about it, if you're exposed to it at 
age 11 or 12, you're jaded by 20 (Avard, 2010)

There is no space for the voices of porn consumers in Dines' account. Rather, using a classic Othering strategy, Dines speaks for them and on behalf of them:

What I've found with my interviews with men is the more they watch, the more they want porn sex, because they become habituated to that kind of industrialstrength sex. Once you become habituated to that, anything else looks boring or uninteresting. What I find is that some men lose interest in their partners altogether and use more pornography. Other men nag and cajole their girlfriends to perform porn sex, or they use prostitutes because that's who they think they can play this porn sex out on (Avard, 2010)

Porn consumers, for Dines, cannot be permitted to represent themselves. They must be represented, by people who will explain to them how harmful their behaviour is. Dines' tour received extensive coverage as she travelled across the world, bringing her academic message through journalistic channels (Bindel, 2010; Dines, 2010a, 2011). A generation of young people was told that they are dangerous, damaged and damaging.

I would like to propose one way of understanding the effects of this Othering, based on personal experience. I recognize the combination of being powerfully drawn to a behaviour, while at the same time being told that the practice was disgusting, wrong, damaged and damaging. This was my experience of being a young gay man in the 1970s and 80s in Scotland. As an adolescent I spent several years as a Christian, desperately struggling to fight off the demon of homosexuality through the power of prayer. Many nights I would lie in the dark, sorely tempted to masturbate, thinking about handsome men - but knowing that these thoughts came directly from Satan who was tempting me in order to draw me away from my Heavenly father. Leaders in my church prayed for me, attempting to cast out the demon of homosexuality. They never succeeded. Too many evenings I would fall into sin, masturbating and then immediately spiraling into depression and self-loathing. I knew that being gay was disgusting and perverse, but I just couldn't help myself. This continued for many years until finally one night, at the age of nineteen, I decided to give up belief in God. It was a blessed relief. 
Thus, when I see the discourses of the damaging effects of porn - rejecting the voices of consumers in order to create a clear picture of their awful despair - I hear an echo of what I went through. As with Christian attempts to stamp out homosexuality, the academic and journalistic Othering of porn consumers says 'We can't stop them from doing it - but at least we can make them hate themselves'. I propose that we can call this the inculcation of self-loathing as strategy. Anti-pornography voices tell young people that, even though 'we' may not have the authority to force 'you', the Other, to stop looking at pornography, we can ensure that you are fucked up about it. We can ensure there are few voices in academia or the news to contradict the assertion of Clive Hamilton, currently a Professor of Public Ethics, who states with confidence in a newspaper story that '[n]o man who regularly uses pornography can have a healthy sexual relationship with a woman' (Symons, 2004, p. 4).

\section{What do porn consumers say?}

The situation is changing. Certainly in academic writing, and occasionally in journalistic news, the voices of consumers are starting to be heard. And when they do so, the picture they paint is far from the sexually damaged portrait painted by psychology, or the desperate addict who appears in journalism. One of the few pieces of academic writing where porn consumers speak for and about themselves is Clarissa Smith's account of interviews with sixteen female consumers of the British pornographic magazine For Women. She notes that 'the motivations of porn readers are rarely examined' (Smith, 2002, p. 1), and that theorists have tended to imagine that ordinary consumers of pornography are unable to have any response beyond sexual excitement:

Only academic, radical feminist or moralist viewers seem able to experience responses other than the 'purely' sexual: they can talk of their boredom. 'Ordinary' porn users are never disappointed, embarrassed, put off, worried, or appalled (Smith, 2002, p. 6).

Smith found from speaking to the sixteen consumers that in fact responses to pornography were highly differentiated, and these women consumed pornography for a variety of reasons. She gives the example of one reader whose husband was not 
interested in her sexually. This woman says that the effect of her use of sexually explicit materials was that: 'it gave me strength ... I didn't feel like my husband was the norm, thank god ... there were blokes out there that did enjoy making love' (Smith, 2002, p. 9).

Another mixed-methods study which combined a large-scale survey with in depth interviews with forty-six consumers of pornography (twenty six men and twenty women) found a diverse range of views among them about how pornography represents sex (McKee, 2005). Some consumers worried that pornography presents a phallocentric view that places the penis at the centre of sexual acts; others were concerned that it fails to show the complexity of sexual negotiations. Several used the word 'education' to discuss their experience of consuming pornography - learning about new practices and positions Related to this issue, other interviewees suggested that pornography, by showing them forms of sexuality that they could relate to but hadn't seen represented before, had the positive effect of reassuring them about their identity, and their right to practise their own sexuality. Other consumers made the point that it doesn't make sense to talk about the 'effect' of pornography on ideas about sexuality without looking at the wider cultural context - on the effect that other media and institutions such as church, family, and education have on attitudes towards sexuality.

The most ambitious attempt to date to allow pornography consumers to represent themselves is contained not an academic publication, but a book by journalist David Loftus. In Watching Sex (Loftus, 2002), he reports on interviews with over one hundred and forty male consumers of pornography. His findings are surprising when compared with the data generated within psychological research: these male pornography consumers

would like to see more plot and romance in pornography ... they do not particularly enjoy close ups of genitals ... they not only do NOT find violence against women or domination of women sexy, they are specifically turned off by such behaviour on the rare occasions they see it in pornography, and most haven't even seen any ... they have not sought ever more vivid, kinky and violent pornography, but have either stuck with what they liked from the first, investigated wilder content and returned to what they preferred, or lost interest 
altogether ... they don't like the way men are portrayed in pornography ... [and] they are against making it available to children, even though many of them were exposed to pornographic stories and images before the age of 12 and don't feel the worse for it (Loftus, 2002, p. xii)

These stories remain on the periphery of the debate, not represented in the dominant discourses around pornography in journalism. And in academia it is still possible for a researcher in 2011 to write in a peer-reviewed article that 'It is difficult to find a methodologically sound study that shows a lack of some kind of harm when men view pornography' (Foubert, Brosi, \& Bannon, 2011, pp. 213-214) (in an article that - of course - involves no voices of actual consumers).

\section{Conclusion}

To conclude I return to the Pringle quotation that opened this chapter: 'we do not consult racists in formulating laws against hate speech on the basis that they are involved in and know a lot about racism' (Pringle, 2011, p. 127). But it could be argued on the contrary that anyone who is interested in reducing racism in a society could find talking to racists a valuable source of information that could help understand why people do what they do - and thus to find ways to address the problem. There is a tradition of academic research that has spoken to sex offenders, for example, in order to understand the reasons for their abuse (see, for example, Beauregard, Stone, Proulx, \& Michaud, 2008; Driemeyer, Spehr, Yoon, Richter-Appelt, \& Briken, 2013). There is no suggestion that these researchers support sexual abuse or approve of sexual offenders. They rather accept that listening to the offenders helps them to understand the problem. In this context the insistent Othering of porn consumers, the refusal even to countenance the possibility of listening to what they say, looks like something quite different from a genuine commitment to understanding the issue. This Othering of pornography consumers by academics and journalists is - as Said puts it in relation to Orientalism - 'neither science, nor knowledge, nor understanding: it is a statement of power and a claim for absolute authority' (Said, 1985, p. 8). He calls for 'an exchange between [their] views and an outsider's ... dialogue ... discussion [and] mutual recognition'. In understanding the consumers of pornography such forms of engagement look like the obvious way forward. 


\section{References}

Anon. (2004, 31st July). Lust junkies flooding cyberspace, Gold Coast Bulletin.

Avard, C. (2010). Interview with Christian Avard. Pulse. http://gaildines.com/2010/07/pulse-media/

Barak, A., \& Fisher, W. A. (1997). Effects of interactive computer erotica on men's attitudes and behavior toward women: an experimental study. Computers in Human Behavior, 13(3), 353369. doi: 10.1016/S0747-5632(97)00014-9

Beauregard, E., Stone, M. R., Proulx, J., \& Michaud, P. (2008). Sexual murderers of children: developmental, precrime and postcrime factors. International Journal of Offender Therapy and Comparative Criminology, 52(3), 253-269. doi: 10.1177/0306624X07303907

Bindel, J. (2010). The truth about the porn industry. the Guardian. Retrieved from the Guardian website: http://www.theguardian.com/lifeandstyle/2010/jul/02/gail-dines-pornography

Boyle, K. (2010). Porn consumers' public faces: mainstream media, address and representations. In K. Boyle (Ed.), Everyday Pornography (pp. 134-146). London and New York: Routledge.

Chronaki, D. (in press). What does news teach about sex? Young people's understandings of the media framing of sexuality. In L. Allen \& M. L. Rasmussen (Eds.), The Routledge Handbook of Sexuality Education. London: Routledge.

Davies, K. A. (1997). Voluntary Exposure to Pornography and Men's Attitudes toward Feminism and Rape. The Journal of Sex Research, 34(2), 131-137. doi: 10.1080/00224499709551877

de Beauvoir, S. (2014 [1949]). The Second Sex. Women and Marxism Archive. Retrieved 22 December, 2014, from http://www.marxists.org/reference/subject/ethics/de-beauvoir/2ndsex/introduction.htm

Dines, G. (2010a). New York Post. Retrieved 29 September 2012, 2012, from http://gaildines.com/2010/07/new-york-post/

Dines, G. (2010b). Pornland: How Porn has Hijacked Our Culture. Boston, Ma: Beacon Press.

Dines, G. (2011, 18 May 2011). How the hardcore porn industry is ruining young men's lives, the Age.

Donnerstein, E., \& Berkowitz, L. (1981). Victim reactions in aggressive erotic films as a factor in violence against women. Journal of Personality and Social Psychology, 41(4), 710-724.

Driemeyer, W., Spehr, A., Yoon, D., Richter-Appelt, H., \& Briken, P. (2013). Comparing Sexuality, Aggressiveness, and Antisocial Behavior of Alleged Juvenile Sexual and Violent Offenders. Journal of Forensic Sciences, 58(3), 711-718. doi: 10.1111/1556-4029.12086

Essig, L. (1999). Queer in Russia: a story of sex, self and the Other. Dunham, North Carolina: Duke University Press.

Fewster, S. (2004, 27 August 2004). Guilty pedophile sobs as judge revokes bail, Adelaide Advertiser, p. 17.

Fisher, W. A., \& Grenier, G. (1994). Violent Pornography, Antiwoman Thoughts, and Antiwoman Acts: In Search of Reliable Effects. The Journal of Sex Research, 31(1), 23-38. doi: 10.1080/00224499409551727

Foubert, J. D., Brosi, M. W., \& Bannon, R. S. (2011). Pornography viewing among fraternity men: Effects on bystander intervention, rape myth acceptance and behavioral intent to commit sexual assault. Sexual Addiction \& Compulsivity, 18(4), 212-231. doi: 10.1080/10720162.2011.625552

Hamilton, C. (2004, 17 August ). Guarding our kids from a perverse twist, the Australian, p. 11.

Kendrick, W. (1996). The Secret Museum: pornography in modern culture. Berkeley, Los Angeles, London: University of California Press.

Lawler, S. (2005). Disgusted subjects: the making of middle-class identities. The Sociological Review, 53(3), 429-446.

Lewis, J. (2008). Presumed Effects of Erotica: Some Notes on the Report of the Commission on Obscenity and Pornography. Film International, 6(6 [36]), 7-16. doi: 10.1386/fiin.6.6.7 
Linz, D. G., Donnerstein, E. I., \& Penrod, S. (1988). Effects of long-term exposure to violent and sexually degrading depictions of women. Journal of Personality and Social Psychology, 55(5), 758-768. doi: 10.1037/0022-3514.55.5.758

Loftus, D. (2002). Watching Sex: How men really respond to pornography. New York: Thunder's Mouth Press.

Malamuth, N. M., \& Check, J. V. P. (1981). The effects of mass media exposure on acceptance of violence against women: a field experiment. Journal of Research in Personality, 15, 436-446.

McKee, A. (2005). The need to bring the voices of pornography consumers into debates about the genre and its effects. Australian Journal of Communication, 32(2), 71-94.

McKee, A., Albury, K., \& Lumby, C. (2008). The Porn Report. Melbourne: Melbourne University Press.

Padgett, V. R., Brislin-Slütz, J. A., \& Neal, J. A. (1989). Pornography, Erotica, and Attitudes toward Women: The Effects of Repeated Exposure. The Journal of Sex Research, 26(4), 479-491. doi: 10.1080/00224498909551529

Pell, G. (2004, 8th August). Crime figures prove we live in an age of violence, Sunday Telegraph, p. 83.

Potter, H. (1996). Pornography: group pressures and individual rights. Sydney: Federation Press.

Pringle, H. (2011). A studied indifference to harm: defending pornography in The Porn Report. In M. Tankard Reist \& A. Bray (Eds.), Big Porn Inc: Exposing the harms of the global pornography industry (pp. 122-133). North Melbourne, Victoria: Spinifex Press.

Richters, J., Grulich, A., de Visser, R. O., Smith, A. M. A., \& Rissel, C. E. (2003). Autoerotic, esoteric and other sexual practices engaged in by a representative sample of adults. Australian and New Zealand Journal of Public Health, 27(2), 180-190.

Sabina, C., Wolak, J., \& Finkelhor, D. (2008). The nature and dynamics of internet pornography exposure for youth. CyberPsychology \& Behavior, 11(6), 691-693. doi: 10.1089/cpb.2007.0179

Said, E. (1985). Orientalism reconsidered. Race and Class, 27(2), 1-15.

Said, E. (1995 [1978]). Orientalism (2nd ed.). London: Penguin.

Shanahan, A. (2004, 12 March). Memo to the gender police: sex is not a morality-free zone, the Australian, p. 13.

Smith, C. (2002). 'They're ordinary people, not aliens from the planet Sex!': the mundane excitements of pornography for women. Journal of Mundane Behavior, 3(1), np. Retrieved from Journal of Mundane Behavior website: http://www.mundanebehavior.org/index2.htm

Strub, W. (2006). Perversion for Profit: Citizens for Decent Literature and the arousal of an anti-porn public in the 1960s. Journal of the History of Sexuality, 15(2), 258-291.

Symons, E. K. (2004, 17th August). Torn on porn's net effects, the Australian, p. 4.

Taylor, P. (2005, 14th April). Child porn "addict" jailed for three years, the Australian.

Zillmann, D., \& Bryant, J. (1984). Effects of Massive Exposure to Pornography. In N. M. Malamuth \&

E. Donnerstein (Eds.), Pornography and Sexual Aggression (pp. 155-138). Orlando: Academic Press, Inc.

\footnotetext{
' Karen Boyle has suggested that the situation is different for fictional representations (Boyle, 2010) - although it should be noted that fictional representations do not present the voices of actual people as does journalism.
} 